\title{
The Impact of Fatherhood on Men's Health and Development
}

\author{
Milton Kotelchuck
}

\section{The Importance of Fatherhood for Men's Health and Development over the Life Course}

This chapter, the second of a pair of related chapters in this volume, provides a broad overview, and new conceptualization, about the various ways in which fatherhood influences the health and development of men. The first, chapter "The Impact of Father's Health on Reproductive and Infant Health and Development", explores the impact of father's health on reproductive and infant health and development (Kotelchuck 2021). Together these two deeply inter-related chapters endeavor to illuminate the here-to-fore under-appreciated topic of the father's importance and necessary active involvement in the perinatal health period, including for his own health and development. [For purposes of discussion in this chapter, the term "perinatal period" will encompass the period from conception into the first few months of life (i.e., pregnancy and early parenthood)].

As noted in the previous chapter, the traditional focus of the U.S.-based Maternal and Child Health (MCH) field (and the closely aligned Obstetric, Pediatrics and Nursing fields) has been on the mother's health and behaviors and their impact on reproductive and infant health and development outcomes. Reproductive health and early parenting has been perceived as primarily, if not exclusively, the mother's responsibility and her cultural domain; and to a significant extent, fathers and men have been excluded. Not surprisingly, as a result, the impact of fatherhood on men's health and mental health, especially in the perinatal period, has not been the subject of much inquiry.

\footnotetext{
M. Kotelchuck ( $\triangle)$

Harvard Medical School and Massachusetts General Hospital Fatherhood Project, Boston, MA, USA

e-mail: mkotelchuck@mgh.harvard.edu
} 
First, these two chapters on father's health are modeled after and build upon the dual orientation of the current women's preconception health movement in the MCH field, which simultaneously addresses the impact of the mother's health during pregnancy on both infant's health outcomes and on mother's own lifetime health. This intergenerational approach respects the integrity and health of both mothers and infants simultaneously, without valuing one's life above the other (Wise 2008). This chapter, like chapter “The Impact of Father's Health on Reproductive and Infant Health and Development", shares this same perspective; together they explore both the father's health contributions to infant health (in the previous chapter; Kotelchuck 2021) and the impact of fatherhood on men's own health (in this chapter) - a virtually new topic in the $\mathrm{MCH}$ literature.

Second, this chapter attempts to create a new conceptual framework that can organize and document the multiple pathways by which the perinatal experiences of fatherhood impact on men's own health and development. By comparison to the previous chapter, there is an even more limited and scattered set of research on this under-explored topic. Several of this chapter's conceptual themes build upon similar themes first expressed in an earlier article on preconception health and fatherhood (Kotelchuck and Lu 2017). This chapter however moves beyond its more limited reproductive health time frame, explores additional, newly evolving paternal reproductive health themes, and separates the reproductive health impacts on infants from those on fathers. This chapter adopts a very broad holistic approach to men's health-blending physical, mental, social and generative health dimensions into a single comprehensive longitudinal fatherhood health framework.

Third, this chapter, like the prior one, also explores the perinatal roots of the impact of fatherhood on men's health and development. Here-to-fore, fatherhood research has been supported primarily by the large, well-established developmental psychology literature that has repeatedly demonstrated positive impacts of father's involvement on multiple facets of child development and family relationships (Lamb 1975, 2010; Yogman et al. 2016; Yogman and Eppel 2021). This chapter aims to more explicitly expand the understanding of men's full life course development as fathers into earlier pre-delivery temporal periods.

Fourth, as noted in the initial associated chapter, this chapter's focus on fatherhood and men's health does not emerge in an ahistorical vacuum, but is linked to, and hopefully contributes to, numerous ongoing political and professional movements. In particular, this chapter is partially embedded in the larger evolving social and gender equity debates over roles and opportunities for women and men in society-especially given that many aspects of parenthood are socially determined and that fatherhood is transitioning from an older, traditional, distant economicprovider, patriarchy model to a newer one based on greater parental equity and paternal engagement. The increasingly large numbers of women who have now entered into the paid labor market, with its associated economic, social, and childcare workplace transformations, is undoubtedly hastening these conversations. This chapter also builds upon the National Academy of Science, Engineering, and Medicine (NASEM) inspired multigenerational child-development efforts to foster effective parenting and parenting health, but now expanded to explicitly include 
fathers (NASEM 2016, 2019). And finally, this chapter derives in part from the emerging men's health movement, with new added emphasis on fatherhood health dimensions.

Fifth, and finally, it is hoped that in articulating the multiple domains of fatherhood's impact on men's health and development, this chapter, along with its companion chapter, will encourage more paternal perinatal health research (both basic and translational), will help guide more effective and targeted father-oriented programs and policies, and will help generate further political will and advocacy for their implementation. These, in turn should further encourage fathers' earlier, more active and healthier involvement in the perinatal health period, strengthen what they bring to, and take from, their fatherhood experiences, and improve their subsequent health and development throughout their life course.

\section{Pathways Through Which Fatherhood Impacts on Men's Health and Development}

There are multiple potential pathways through which the experiences of fatherhood could have an impact on men's health and development during the perinatal pregnancy and early parenting period and over their life course. This chapter will note and briefly explore the scientific evidence base for six distinct pathways. These fatherhood health pathways, in turn, also directly and indirectly influence the current and intergenerational health and well-being of their infants, partners, families, and communities. Specifically,

1. Men's physical health status during the perinatal period (pregnancy and early parenthood)

2. Changes in father's physical health during the perinatal period: Impact of Fatherhood on Men's Physical Health

3. Changes in father's mental health during the perinatal period: Impact of Fatherhood on Men's Mental Health

4. Changes in father's social health and well-being during the perinatal period: Impact of Fatherhood on Men's Social Well-being

5. Men's psychological maturation of paternal generativity: Men's Improved Capacity for Parenthood and Fatherhood

6. Men's life course development of fatherhood.

\subsection{Men's Physical Health Status During the Perinatal Period}

Men's physical health during the pregnancy and early parenthood period has a much more important and direct impact on reproductive and infant health than perhaps 
most $\mathrm{MCH}$ professionals and parents have here-to-fore understood (Kotelchuck 2021). Given the traditional cultural focus on mothers and their well-being, the topic of father's health has not drawn much attention. However, and perhaps not surprisingly, given men's generally sub-optimal health status and health care utilization, men's physical health status during perinatal period reveals substantial health problems and potential opportunities for its improvement.

Ascertaining men's health status on a population-basis during their prime reproductive years has been methodologically challenging, and possibly here-to-fore of limited reproductive health interest. Although some broad longitudinal epidemiologic data sets exists for men of childbearing ages, they are not usually stratified by parenting status; the NHANES survey, for example, appears to have no publications describing father's health. Yet health status may differ for men between pre- and post-fatherhood years. In general, though, matched-age fathers initially should be healthier than non-fathers, as men with a wide variety of health issues are less likely to achieve successful fertility (CDC 2019; Frey et al. 2008).

Choiriyyah et al. (2015) examined the 2006-2010 US National Survey of Family Growth, which suggested that $60 \%$ of men aged 15-44 were in need of preconception healthcare; $56 \%$ were overweight or obese; $58 \%$ binge drank in the last year; and $21 \%$ had high sexually transmitted infection (STI) risk. Pre-pregnancy overweight and obesity is a more pervasive problem for men than for women (53\% vs. 29\%) (Edvardsson et al. 2013), a fact which takes on added importance since men's obesity is an independent predictor of childhood obesity (Freeman et al. 2012). One might assume that fathers in the pregnancy and early parenthood period would continue to still have a similar set of broad health risks. The MGH Obstetrics Prenatal Fatherhood studies (Levy and Kotelchuck 2021) noted nearly $75 \%$ of antenatal fathers are overweight (including $25 \%$ obese), reflecting their self-reported low physical activity, high sedentariness and extensive media usage; plus $14 \%$ of fathers revealed signs of infertility or delayed fertility. Smoking rates are highest among men during childbearing years. For example, almost $30 \%$ of men aged 20-24, and 25\% of men aged 25-34 smoked in Canada (Canadian Tobacco Use Monitoring Survey 2006).

Men are well known for their lesser use of health services than women, even adjusting for women's reproductive health services usage (Bertakis et al. 2000; Smith et al. 2006). Perhaps due to their own social construction of masculinity, men differentially ignore screening and preventive health care and delay help seeking for symptoms (Smith et al. 2006; Addis and Mahalik 2003). Yet the opportunity for care exists, as most men $(\sim 70 \%)$ in the US would appear to receive primary health care annually (Choiriyyah et al. 2015; Levy and Kotelchuck 2021). However, too many receive no preconception health care at those visits; Choiriyyah et al. (2015) reported very limited receipt of STI testing $(<20 \%)$ or counseling $(<11 \%)$ services.

Perhaps similar to women, the pregnancy and early parenthood period could be an opportune time to address men's health needs overall. Limited, one-time, self-reported assessments of father's health status during the preconception and antenatal periods suggest that there is much room for improvement in men's 
own physical health and health care utilization. There remains however great need for more creative epidemiological studies of men's overall health during his prime reproductive years, specifically stratified by fatherhood status.

\subsection{Changes in Father's Physical Health During the Perinatal Period}

Pregnancy and early parenthood are associated with four broad sets of changes in father's physical health status: paternal weight gain; sympathetic pregnancy (couvade) symptoms; brain and hormonal transformations; and increased longevity.

\subsubsection{Paternal Weight Gain}

Fatherhood, on a population basis, is associated with increased weight and elevated Body Mass Index compared to comparable aged men who are not fathers. Using the American Changing Lives panel data, Umberson et al. (2011), showed that fathers have more accelerated weight gain throughout their life course and weigh $\sim 14 \mathrm{lb}$ more than non-parental males. Garfield et al. (2016), using the National Longitudinal Study of Adolescent to Adult Health (ADD Health) data base, documented that the transition to fatherhood was associated with an additional weight gain of 3.5-4.5 lb more for residential fathers than for non-residential fathers or non-fathers.

Moreover, the popular literature has noted and commented extensively on the "Dad Bod" or "preg-MAN-cy weight." One widely cited informal British study estimates that new fathers gain $11 \mathrm{lb}$ over the course of the pregnancy, speculating that they partake in their partner's binge eating, finish up the left over foods, eat out more in restaurants, and increase eating to respond to their own stress (BBC News 2009). Saxbe et al. (2018) more formally assessed seven possible behavioral, hormonal, psychological, and partner mechanisms for the increased weight gain in fathers; they concluded the likely sources included decreased sleep, less exercise, less testosterone, more stress, and partner effects (shared diets).

Specifically, the transition to fatherhood is associated with significant sleep disturbance and disruption (e.g., partnered men with young children sleep approximately 80 fewer hours per year than single, childless men (Burgard and Ailshire 2013)) and reduced time available for men's own leisure and exercise (e.g., 5 h/week decrease in physical activity with the first child and a further $3.5 \mathrm{~h} /$ week decrease with a subsequent child (Hull et al. 2010)). Parenting-associated physical activity declines are more pronounced for men than for women. Fatherhood was not associated with changes in men's diet (Saxbe et al. 2018). Paternal pregnancy weight gains set the stage for men's greater obesity morbidity throughout their lives (Umberson et al. 2011; Saxbe et al. 2018). 


\subsubsection{Couvade Syndrome}

In many cultures, fathers experience "Couvade syndrome" or "Sympathetic pregnancy"; that is, physical and psychological symptoms and behaviors that mimic the expectant mother's during her pregnancy and post-partum period (Kazmierczak et al. 2013), including insomnia, nausea, headaches, toothaches, abdominal pain, as well as increased stress and weight gain. Couvade is not a recognized (DSM-5) mental illness or (ICD-10) disease. Thus, the extent of couvade syndrome's prevalence has been difficult to ascertain, and estimates vary widely, from $11 \%$ to $65 \%$, depending on the symptoms and populations being assessed (Masoni et al. 1994). Symptoms seem most common in the first and third trimesters, and most subside after the baby is born (Brennan et al. 2007). The sources of couvade in men remain elusive, drawing extensive psychological and psychosomatic theorizing (e.g., empathetic responses to pregnancy; compensatory or even competitive symptoms; or shared hormonal changes) (Kazmierczak et al. 2013). So called "primitive couvade," is associated anthropologically with male pregnancy rituals, in which men refrained from, or partook in special antenatal or birthing rituals thought to impact the spirit of the developing child. Couvade symptoms are associated with increased paternal health service utilization, though they are often unrecognized or associated with their partner's pregnancy status (Lipkin and Lamb 1982).

\subsubsection{Biologic Adaptions: Hormonal and Brain Structure Transformations}

While it has long been noted that women's hormones change or adapt as a function of motherhood (Fleming et al. 1997; Edelstein et al. 2015), there is also now growing evidence of men's biologic adaptation to fatherhood (Edelstein et al. 2015; Gettler et al. 2011; Grebe et al. 2019). Testosterone, which is important to male sexuality, mating and aggression, declines notably as men prepare to assume enhanced parental roles. Testosterone levels are lower among fathers than non-fathers (Grebe et al. 2019), decline over the course of pregnancy (Edelstein et al. 2015), and further decrease among fathers who more actively provide infant care compared to men who provide little or no care (Grebe et al. 2019). The synchronous decline in paternal and partner's testosterone levels during pregnancy is associated with stronger postpartum relationship investment (Saxbe et al. 2017). Among the $\sim 6 \%$ of animal species where males participate in parenting activities, the post-conception internal regulation of testosterone levels increases the Darwinian survival of their children (Grebe et al. 2019). Other paternal hormones: estradiol (Edelstein et al. 2015); oxytocin (Gordon et al. 2010); and prolactin (Hashemian et al. 2016) increase in men over the course of pregnancy and early post-partum period; and all are associated with increased child care, nurturing behaviors, and engagement in both men and women. 
The term "Dad Brain" has also gained some prominence in the popular literature, perhaps inadvertently reflecting the new beginning exploration and documentation of the plasticity of men's brain structure associated with parenting. There is growing evidence that both fathers and mothers neurally process infant stimuli in similar manner (e.g., the global parent caregiving neural network) (Abraham et al. 2014). Paternal brain plasticity is associated with greater paternal caretaking involvement, especially in the social-cognitive pathway network (e.g., the amygdala-superior temporal sulcus brain connectivity), which in part allows men to better infer infant mental states from their behavior (Abraham et al. 2014). Fathers, like most mothers, can recognize and pick out their own infant's crying, but only if they spend extensive time daily with them (Gustafsson et al. 2013). Moreover, within the first 4 months postpartum, there are changes in the volume of gray matter in the regions of the paternal brain involved in motivation and decision-making (Kim et al. 2014), further suggesting plasticity in father's brain after becoming a parent. Additionally, there is an extensive and growing animal research literature showing paternal brain structure changes with active fatherhood, especially among prairie voles (Rolling and Mascaro 2017).

\subsubsection{Paternal Longevity}

And finally and positively, fathers live longer than men without children, even controlling for marital status (Modig et al. 2017; Grundy and Kravdal 2008; Keizer et al. 2011), similar to that reported for mothers. The longevity impact of parenthood is stronger for men than women (e.g., 2.0 vs. 1.5 years greater life expectancy gap at 60 years of age (Modig et al. 2017)), and for fathers with 2 or 3 children versus none (Grundy and Kravdal 2008; Keizer et al. 2011). As men age, fatherhood could be a source of deep emotional satisfaction, as well as companionship and non-isolation. Alternatively, these longevity findings may also reflect a confounding of healthier men being more likely to wed and have children, which then play out over their life course.

Father's physical health is much more profoundly affected by the onset of early fatherhood than perhaps most of the existing popular and professional literature here-to-fore would have assumed. During the perinatal period and likely beyond, father's minds and bodies, like the mother's, adapt biologically to their new parenting roles-perhaps preparing them for the physical and mental stresses, joys, and requirements of parenthood. The changes in men's physical health associated with fatherhood should encourage both greater attention to paternal health promotion activities and increased utilization of reproductive and primary health care services during the perinatal time period and beyond. Basic research on this topic is now just beginning, with the emerging interest in father's perinatal health. 


\subsection{Changes in Father's Mental Health During the Perinatal Period}

Pregnancy and the onset of parenthood is a time of substantial mental health transition for men-as it is for women (Singley and Edwards 2015). There is greater awareness and recognition of fatherhood's impact on men's mental health than on his physical health. Perhaps the greater awareness of perinatal mental health issues is due to the growing appreciation of perinatal depression on maternal and infant health and the increasing calls to similarly address paternal mental health needs by the family sociology, clinical psychology, and nurse-midwifery communities (May and Fletcher 2013; Baldwin and Bick 2018). Men's mental health responses to fatherhood are very salient during pregnancy and early parenthood-both as sources of stress and of growth and love. And in turn, father's mental health status profoundly influences maternal reproductive and parenting health and infant health and development (Kotelchuck 2021; NASEM 2016, 2019).

Parenthood, especially for first time fathers, is an unknown and unfamiliar event, out of his normal control (Baldwin et al. 2018); multiple potential sources of perinatal stress emerge, including the changing relationship with the mother, added financial obligations, and concerns over the ability to be a competent parent (Coleman and Karraker 1998; Singley and Edwards 2015). Moreover, given limitations in parenting- and sex-education in schools and in gender role experiences developmentally, most men have limited or no understanding about pregnancy biology, perinatal health services, or practical parenting skills. They often feel helpless about what to do or expect as they enter into fatherhood. Postnatally, fathers confront additional new concerns about work-family balance, childcare logistics, all while sleep deprived, and often with limited social or peer support to help them adjust to their new fatherhood roles. Moreover, today, men, especially first-time fathers, are further challenged to create a new internal fatherhood identity for themselves (Baldwin et al. 2018), and often with deep conflicting fatherhood gender role expectations at play (Singley and Edwards 2015). Most men today were raised in an era with more traditional male gender roles and now are being confronted with expectations for more engagement and equity in childcare, roles that some men may perceive as more feminine or weak; i.e., something of a fatherhood generation gap exists today. Overall, these and many other factors contribute to a potent brew of men's mental health challenges in the pregnancy and early parenting period.

\subsubsection{Paternal Stress, Anxiety and Depression}

Paternal stress. Given the formidable parental role transformations associated with fatherhood, not surprisingly, there are numerous reports of elevated paternal stress associated with pregnancy and early parenthood. A review article by Philpott et al. (2017) located 18 quantitative studies on paternal perinatal stress, 11 with elevated stress levels. Paternal stress increases continuously throughout the antenatal period, 
peaks at birth and then declines afterwards. The principle factors identified that contribute to paternal stress included negative feelings about the pregnancy, role restrictions related to becoming a father, fear of childbirth, and feelings of incompetence related to infant care. Higher stress levels negatively impact father's health and mental health, contributing to increased anxiety, depression, psychological distress, and fatigue (Philpott et al. 2017).

The MGH Obstetric Prenatal Fatherhood studies (Levy and Kotelchuck 2021) reinforce these observations antenatally; $\sim 56 \%$ men endorsed the observation that pregnancy is associated with high levels of paternal stress; with concerns focused on financial issues (44\%), ability to care for the baby (29\%), less time for self $(20 \%)$, changing relationship with mother $(15 \%)$, and not repeating their father's mistakes (14\%). Further, 35\% of men reported not having any place or person to go to for fatherhood support, which likely further added to their stress symptoms.

Paternal anxiety. Substantial levels of clinical anxiety disorders are found among men during the perinatal period. A recent systematic review by Leach et al. (2016) reported the prevalence rates of anxiety disorders in men ranged between $4.1 \%$ and $16.0 \%$ during the prenatal period and $2.4-18.0 \%$ during the postnatal period. [As compared to a 13.0\% rate in general population of men (McLean et al. 2011).] Anxiety disorders increase steadily throughout antenatal period and then decline after birth (Philpott et al. 2019). Factors contributing to anxiety disorders included lower income levels, less co-parent support, fewer social supports, work-family conflict, partner's anxiety and depression, and paternal anxiety history during a previous birth. Higher anxiety levels increase paternal stress, depression, fatigue, and lower self-efficacy (Philpott et al. 2019). The few behavioral or education trials to reduce paternal anxiety, to date, have all been successful (Philpott et al. 2019).

Paternal depression. There are numerous reports of elevated levels of depression associated with fatherhood. A meta-analysis of the prevalence of men's depression in the perinatal period (Paulson and Bazemore 2010) showed higher rates of paternal depression $(10.4 \%)$ than in similar aged men in the general population (4.8\% over a 12-month period) (Kessler et al. 2003). Garfield et al. (2014), using the ADD Health data, documented that new fathers were 1.68 times more likely to be depressed compared to comparable aged men without children, and that resident father's depression symptoms increased from before pregnancy through the pregnancy and beyond. The Paulson and Bazemore (2010) analysis documented substantial rates of paternal depression throughout the pregnancy: $11 \%$ in first and second trimester and $12 \%$ in third trimester; and then varied rates throughout the first year post-partum: $8 \%$ at $1-3$ months, peaking at $26 \%$ at 3-6 months, and then $9 \%$ from 6 to 12 months.

When stratified by country, paternal depression rates are higher in the U.S. (14.1\%) than in the rest of the developed world (Paulson and Bazemore 2010), perhaps associated with the lack of childcare support and paid parental leave in the U.S. (Glass et al. 2016). Paternal depression is strongly correlated ( $\mathrm{r}=\sim .30$ ) with maternal depression (Ramchandani et al. 2008; Paulson and Bazemore 2010), though prevalence rates are consistently higher for mothers. In the MGH Obstetric Prenatal Fatherhood studies, 26\% of the antenatal fatherhood sample endorsed at least one of the two PHQ-2 depression screener symptoms, with 
$8 \%$ reporting more severe or frequent symptoms (Levy and Kotelchuck 2021). A wide variety of risk factors have been linked to paternal depression; including prior mental health depression experiences, changing paternal hormones, lack of social supports, maternal depression, and poor relationship satisfaction (Singley and Edwards 2015; Gemayel et al. 2018).

Paternal post-partum depression. Increasingly, there has been a heightened awareness that post-partum depression (PPD) is not restricted to only women, and that men also experience PPD (Kim and Swain 2007; Ramchandani et al. 2008; Singley and Edwards 2015). Paternal PPD is increasingly recognized as a chronic condition, with the $10 \%$ prevalence rate from the Paulson and Bazemore (2010) meta-analysis widely quoted. Ramchandani et al. (2008), using the Avon Longitudinal study (ALSPAC) found the highest predictors of paternal PPD to be high prenatal anxiety, high prenatal depression, and a history of severe depression; findings consistent with a more recent meta-analysis (Gemayel et al. 2018).

\subsubsection{Behavioral and Externalizing Mental Health Impacts}

The mental health consequences of fatherhood aren't only manifested internally, but also through externalizing behaviors. Men often express their depression, stress, or anxiety through "self-medicating" drinking, over-eating, interpersonal anger, or physical absence. Intimate partner violence (IPV), for example, is known to be markedly elevated after conception and again after delivery (Nannini et al. 2008). Many new fathers retreat to over-working at their employment (the traditional model of fathers as providers) to partially withdraw from their infant care and family involvement and associated stresses (Singley and Edwards 2015; Baldwin et al. 2018). Research on this topic is limited, although theoretically, many negative paternal perinatal health behaviors can be interpreted as mental health linked.

\subsubsection{Positive Mental Health Impacts}

While fatherhood is a time of much negative emotional stress, it is also a time of deep joy, happiness, and satisfaction for most men. While most qualitative studies of men's mental health during the perinatal period acknowledge positive emotional responses, few have explored them in detail. Baldwin et al.'s (2018) systematic review of this topic noted that paternal satisfaction resulted from achieving mastery, confidence, and pleasure over the reality of dealing with a newborn, becoming a competent father, and doing it in a constructive way with one's partner. Moreover, some men's negative health behaviors change for the better as they move into their new parental roles, similar to many women. In the Fragile Families and Child Well Being Study, for example, among low-income urban fathers, fatherhood was associated with more healthy behaviors and decreased substance use (Garfield et al. 2010). In this chapter's subsequent fifth section (Sect. 2.5), the positive impact of 
fatherhood on men's psychological development and generativity is further explored.

\subsubsection{Perinatal/Infant Specific Sources of Paternal Depression}

The post-partum mental health impact of fatherhood has bi-directional roots; it can be influenced by the infant's health and behavior characteristics, not just by men's own psychological responses to the pregnancy and his new paternal and family roles.

Fatherhood and pregnancy loss. While there is a robust literature on the impact of fetal loss on mothers' mental health, the equivalent literature for fathers is very limited. A summary review by Due et al. (2017) identified only 29 articles on paternal responses to fetal loss versus 3868 articles on maternal responses. They concluded that fathers primarily feel the need to be supporters of their partners, but that they also feel overlooked and marginalized about their own responses to the loss. Fathers, like mothers, experience a loss of parental identity and of parental hopes and dreams for their deceased infant, though these negative emotions appear less enduring for fathers. There is a striking absence of informational brochures or clinical materials specifically directed towards fathers to help them deal with the emotional trauma of fetal loss.

Fatherhood and prematurity. Fathers of premature or low birth weight (LBW) infants are more likely than mothers to experience post-partum depressive symptoms (Cheng et al. 2016). This takes on added significance since paternal depression is also an independent predictor of subsequent child development (Cheng et al. 2016). Interventions to address the mental health needs (including depression) of parents of infants in NICUs are increasing, but only some are directed at both parents (Garfield et al. 2014).

In sum, the perinatal period is a time of significant mental health transition for fathers, especially first-time fathers, as they address the multiple new challenges of fatherhood. Fatherhood is associated with both substantially elevated levels of stress, anxiety, and depression, as well as joy, pride, and emotional maturation. Interest in men's perinatal mental health derives heavily from the increasing appreciation of maternal depression and its impact on reproductive and child outcomes. Paternal mental health has been the main initial area of focus for the exploration of the impact of fatherhood on men's health. Moreover, men's perinatal mental health necessarily engages with important cultural crosscutting themes such as contemporary masculinity, family gender roles, and work-life balance. Only recently has there begun to be any, even slight, professional recognition of men's own mental health needs in the perinatal period, and virtually no mental health services are directed towards them. 


\subsection{Changes in Father's Social Health and Well-Being During the Perinatal Period: The Impact of Fatherhood on Men's Social Health and Well-Being}

Fatherhood doesn't only influence men's physical and mental health, but also his social health and well-being. Fathers differ from non-fathers in their social connections, family relationships, and work behavior (Eggebeen and Knoester 2001). Each of these can directly impact maternal, infant, and men's health and development. While the $\mathrm{MCH}$ reproductive health community (and popular culture) widely acknowledges and embraces the women's changing social roles (and prestige) as new mothers, the same is not true for the social transformative impact of men becoming fathers. By contrast, many other professional communities, in business, social welfare, governmental policy, and economics, have grappled more with men's social well-being and how it is impacted (positively and negatively) by fatherhood, especially as it relates to gender role equity at home and work (Bowles et al. 2021). Indeed, most of this larger book focuses on father's social well-being in society. This topic also reflects, in part, the emerging social determinant of health (SDOH) perspectives in the $\mathrm{MCH}$ community, recognizing that fathers are often the main vector for family's SDOH (Kotelchuck 2021). However, importantly here is a new recognition that the father's social well-being (and SDOH characteristics) are not static but are malleable during the perinatal period.

\subsubsection{Fathers as Employees}

Fatherhood has the potential to profoundly challenge men's relationship to his employment and his traditional employee social roles. Fathers now face new, competing, and deeply-valued societal pressures: to be engaged nurturing fathers and to continue to be economically productive employees (Hobson and Fahlen 2009). New fathers experience substantial added social role conflicts over work versus family life (Baldwin et al. 2018; Harrington 2021; Ladge and Humberd 2021). These may further heighten men's own conflicting internal cultural views about the nature of work and the newer involved fatherhood concepts of this eraespecially since most men's identity and sense of masculinity is heavily influenced by his employment/career and its associated income (Humberd et al. 2015; Ladge and Humberd 2021). Men, in general, increase work hours post-delivery, perhaps in part to meet the growing family economic needs and to further assume men's traditional breadwinner social roles (Hodges and Budig 2010). Men's post-delivery work experiences as a father can become a critical arena for impacting his health, mental health, and sense of responsibility for his family's well-being. [Many of the subsequent chapters in this book examine the social health and well-being challenges that new working fathers experience in trying to achieve a healthier work-life balance, and the employment and social welfare policies and practices that could help alleviate them.] 
Second, on a more positive note, for some fathers, employee-based paid paternal newborn leave provides a special opportunity for their psychological and practical growth as parents (i.e., paternal generativity). Fathers who take 2 or more weeks of leave are more involved in direct childcare at 9 months (Nepomnyaschy and Waldfogel 2007), are more likely to remain in their marital relationship (Petts et al. 2019), and to enhance their partner's health and wealth (Persson and RossSlater 2019); though the direct benefits for fathers of paid paternal leave have been less well researched. Short or no paternal newborn leaves, in general, are associated with difficulties establishing a sense of paternal identity, paternal confidence, and competence in caregiving, and more work-family stress (Harrington et al. 2014).

Third, fatherhood, like for motherhood, can contribute to men's capacities to be a better employee. Father's psychological development and maturity, and the skills of parenthood, often carry over into the workplace, including better self-managerial skills, enhanced time management, focus, patience, responsibility, and leadership (Ladge and Humberd 2021). Fathers at work are perceived as more kind, compassionate, and mature (Humberd et al. 2015), and builders of social connections and bonds (Ladge and Humberd 2021). Among men with similar skill levels and CV's, fathers are more likely to be offered a position (Correl et al. 2007). There is a growing recognition within business communities, especially their human resources professionals, that more family- (and father-) friendly workplaces are associated with higher productivity and profits than traditional workplaces-possibly through more motivated, loyal, and skilled employees, with less work-family conflict, staff turnover, and burn out (Ladge et al. 2015; Ladge and Humberd 2021; Harrington 2021).

\subsubsection{Fathers as Family and Community Members}

It is widely believed that fatherhood, for most men, draws them ever more tightly into their family and community; and, in general, men do adapt to society's fatherhood expectations and family social welfare responsibilities, no matter what their personal perspectives are on the nature of fatherhood. The $\mathrm{MCH}$ reproductive and child development communities acknowledge this important paternal social role transformation, but mostly from a negative or deficit perspective, focusing heavily on father-absent or "deadbeat dad" families. Rarely, does the MCH community discuss paternal family commitment and community involvement from a majoritarian perspective that focuses on father's positive transformative social well-being. [The impact of the non-residential father-absence on children and men's development is discussed, in part, by others in this book (Yogman and Eppel 2021).]

First, the vast majority of fathers readily acknowledge their paternity. Historically, acknowledgement of paternity was related to infant legitimacy and inheritance, and was closely tied to the marital status of the father and mother. Despite increases in births to unmarried parents ( $40 \%$ of U.S. births) (Martin et al. 2019), the rate that men embrace and acknowledge their paternity is increasing (Almond and Rossin-Slater 2013); perhaps a reflection the increased legal mandates to establish an "Acknowledgement of Paternity" (AOP) for each birth to an unmarried 
mother in the U.S. Birth outcomes among unmarried women with partners who sign an AOP were significantly better than among unmarried women without an AOP, though still not as positive as among married women (Almond and Rossin-Slater 2013.)

Second, though obviously a partnered decision, the vast majority of fathers reside with and support their families financially, practically, and emotionally during the perinatal period and beyond (whether married or not). Clearly, over time the extent of this involvement does decline, especially among poorer and unmarried families. In the U.S., among Fragile Families Study participants, only 50\% of unmarried couples cohabitating at birth are still living together at the child's first birthday, and just $37 \%$ are by the child's fifth birthday (Carlson et al. 2008). But even among the non-residential fathers studied, fatherhood serves as a source of engagement and social well-being for themselves and their children; the majority saw their children at 1 year of age and provided informal and in-kind support (Carlson et al. 2008); fatherhood gave meaning to their lives (Garfield et al. 2010). Married marital status increasingly is a marker of higher social classes, conveying social and developmental benefits for the father and his children (McLanahan et al. 2013). Moreover, fatherhood is not restricted solely to biologic fathers, many other men assume parental roles, nearly $4 \%$ of U.S. children under age 6 live with a mother and a step-father (Census 2018). The father's continued involvement and presence in his family can be viewed, in part, as a bi-directional impact of fatherhood on men's social well-being - a positive behavioral response to stresses and joys of parenthood and his relationship with the child's mother.

Third, positive perinatal cultural and institutional support for men's social transition to fatherhood is quite limited. Many community and professional organizations and cultural practices are prepared to honor women's new maternal social role and to welcome her and her infant into their communities (e.g., baby showers, prenatal yoga classes, maternity stores, etc.). There are no similar equivalent positive cultural acknowledgements for men's changing social roles. With the exception of limited father-inclusive child-birth education classes, most maternal reproductive health services do not actively encourage father's involvement or acknowledge his new emerging fatherhood status (Steen et al. 2012). Moreover, fatherhood, like the experiences for some women, can also sometimes reveal or increase men's social isolation from their communities. In the MGH Obstetric Prenatal Fatherhood studies, $35 \%$ of fathers reported that they had no place to go for fatherhood support or information (Levy and Kotelchuck 2021). Fatherhood and men's family and community involvement needs greater and earlier perinatal social affirmation. If it takes a village to raise a child, that village needs to include the fathers.

\subsubsection{Fathers as Economic Providers: Fathers Own Lived SDOH Transformations}

Most father's and family's economic realities are transformed as a result of parenthood. Families, almost by definition, have decreased per capita income and 
substantial new direct childcare expenses, though some potential new financial resources. The impact of fatherhood on the transformation of men's own social and economic welfare, his own lived social determinants of health (SDOH) characteristics, has yet to emerge as a topic in the $\mathrm{MCH}$ reproductive health community.

First, fathers are eligible for some societal benefits that favor families relative to single or married men without children. The latter are often restricted from social welfare benefits, such as paid paternity leave or family allowances, or are the last to receive access to public housing, food-assistance, or medical care programs-a positive discrimination in favor of fathers. Tax benefits in the U.S., including direct child, child and dependent care, and earned income tax credits (EITC), in general, also favor working families, and therefore fathers with children.

Second, economists have documented a "fatherhood wage bonus," and women's income "motherhood penalty." In adjusted analyses, fathers earn $6 \%$ more salary than non-fathers (Budig and Hodges 2014). Additionally, the wage gaps between employed men and women increases substantially for parenthood; non-parent women earn $93 \%$ of non-parent men's salary, whereas, working mothers earn only $76 \%$ of father's wages (Budig and Hodges 2014); plus, this wage gap is even greater for low-income fathers and mothers, further reinforcing social disparities. In some employment situations, fatherhood is associated with a "fatherhood premium," increased wages to be able to support their families (Correl et al. 2007).

Third, fatherhood can, however, also limit or harm men's social health and financial status, especially for non-residential, low income, and minority fathers, whose social welfare benefits are heavily influenced by federal and state government programs and policies. U.S. policies often both encourage and discourage paternal involvement with their families_-perhaps reflecting the current political ambivalence towards such fathers and their partners (Edin and Nelson 2013). Many social welfare programs are structured to penalize or limit benefits for non-residential, non-married fathers. Traditional U.S. family welfare and Medicaid eligibility was explicitly restricted to mothers without residential male partners. Aggressive federal and state child support enforcement agency efforts, while potentially enhancing mother's income, often inadvertently decrease father's family involvement, by further burdening the poorest men with high arrears penalty interest rates, asset seizures, and possible incarceration (Tollestrup 2018; Boggess et al. 2014). And the U.S. "War on Drugs" disproportionately ensnared poor men (and often fathers) of color. The major U.S. federal Healthy Marriage and Responsible Fatherhood Initiative (ACF 2019) primarily emphasizes the father's traditional social and financial family roles; it provides low income men with relational skills and marriage motivational training, though not direct income or social welfare supports. Its initial program evaluations were mixed (Knox et al. 2011); perhaps its limited, politicallyinfluenced, individual responsibility training model may be insufficient to overcome the structural realities for poor fathers in the U.S. Other countries, especially in Europe, provide more positive supports for father's social well-being as part of their more universal family social welfare policies-including father-specific paid family leave and family allowances (see, e.g., Kvande 2021, in this volume). 
Overall, men's own social health and well-being is impacted by their experiences of fatherhood-in employment, family, community involvement, and economic resource provisions. Each of these social experiences of fatherhood are important influences on men's physical health, mental health, and paternal generativity, which in turn can directly impact reproductive and infant health and development. While the social transformation of women into mothers is widely acknowledged and celebrated, a similar recognition of the social health transformation of men becoming fathers is lacking-especially in the MCH reproductive health community. Fatherhood can change men's own SDOH characteristics, though the extent may depend on the unique employment and social welfare policies and practices within each country. The United States, in particular, has weak and often punitive social welfare policies that substantially impact on low income and non-residential fathers. Further reproductive health research on the social impact of fatherhood is needed.

\subsection{Men's Psychological Maturation of Paternal Generativity: Men's Improved Capacity for Parenthood and Fatherhood}

Fatherhood can be a major influence on men's own adult psychological development and maturation, especially during his first pregnancy and early parenthood experience. This transformation represents one of most important health impacts of fatherhood. Virtually all men can biologically procreate children, but it takes more than just sperm to become a father. Having children is a powerful biologic urge that can profoundly affect men and women's psychological maturation. Many fathers, similar to most mothers, go through substantial psychological transformations and growth during the perinatal period. Fatherhood can be viewed as an adult psychological developmental stage of life.

Psychological transition to fatherhood. In reviews of men's psychological transition to fatherhood studies, Genesoni and Tallandini (2009) found pregnancy to be the most demanding period for the father's psychological reorganization of self, and labor and birth to be the most emotional moments. Baldwin et al. (2018) characterized some of the most salient features of men's positive psychological transition into their new fatherhood identity: "Becoming a father gave men a new identity, which made them feel like they were fulfilling their role as men, with a recognition of changed priorities and responsibility and expanded vision; however they worried about being a good father and getting it right.... Fathers who were involved with their child and bonded with them over time found the experience to be rewarding. Those who recognized the need for change, adjusted better to the new role, especially when they worked together with their partners." Beyond the limited and predominantly qualitative professional literature, this developmental transition is perhaps best noted in the popular media through movies and television shows that 
capture the profound paternal psychological transformation of men as a result of parenthood (e.g., Kramer vs. Kramer; Mrs. Doubtfire; Three Men and a Baby; and, more recently, Marriage Story).

There are numerous different terms used to describe this developmental transformation in men from biological procreation to responsible fatherhood. For many, it is commonly and best discussed in terms of life fulfillment, or even of religious or spiritual goals (e.g., "Fatherhood as the highest calling in life"). I prefer to use the psychological term of "generativity" to describe this transformation; it is a term coined by Dr. Erik Erikson (1950) and defined as "establishing and guiding the next generation, with a capacity for love and sense of optimism about humanity" (i.e., successfully nurturing the next generation). Hawkins and Dollahite (1997); Dollahite et al. (1997), and Hawkins and David (1997) have expanded on this concept and coined the term "generative fathering," a perspective on fathering rooted in the ethical obligations for fathers to meet the needs of the next generation. They conceptualize fathering as generative work, rather than as a social role, embedded in a changing socio-historical context from which both fathers and children benefit and grow. Singley and Edwards (2015) interpret the term generative fathering to describe the type of parenting used by fathers who respond readily and consistently to their child's development needs over time, a key element of Erik Erikson's adult development theory, rooted in broadening the sense of self to include the next generation. The generative fathering perspective highlights a clear way that men can focus their instinct to protect and to provide for their children in a strengthsbased way - by being involved and responsive to their children's needs even from their earliest (antenatal) age. Moreover, the concept of generativity, or generative fathering, adds an internal motivational and a moral dimension to men's ongoing psychological transformation in becoming fathers, a sense of paternal agency. Men themselves are, and must be, the agents of their own psychological transformation.

Even for the most marginalized fathers, creating and nurturing life is perceived as one of the most meaningful statements about one's presence on earth and contribution to life (Edin and Nelson 2013). In the Fragile Families and Child Well Being Study, fatherhood was associated with being present for their child's future (Garfield et al. 2010). From a parallel perspective, Roubinov et al. (2016) describe "familism" in Latino (specifically, Mexican-origin) communities as a father's deep ethical and cultural commitment to nurturing his children and family, even if also deeply imbued with a "machismo" social-roles perspective. Additionally, the Black women's reproductive justice movement is now also beginning to recognize the importance of reproductive and economic justice for their impoverished Black male partners as well (e.g., Edwards et al. 2020).

As fathers are increasingly present with their partners in the delivery room, there is now a growing literature on its transformative effects on men's psychological development (Genesoni and Tallandini 2009; Darwin et al. 2017; Baldwin et al. 2018; Johansson et al. 2015). Fathers can share the joy and miracle of birth, be supportive of their partners, and further crystalize their own paternal role transition. However, many men report very mixed experiences in the delivery rooms, with clinical staff not always supportive of their presence (Steen et al. 2012; Jomeen 
2017). Only recently have a few birthing services intentionally tried to enhance the father's contributions and engagement, both to foster a more positive family-forming health event and to support men's own psychological development as fathers (Pol et al. 2014; Johansson et al. 2015).

Programmatic support for men's psychological transition to fatherhood. Fatherhood psychological transition is not universal. Generative or responsible fathers don't just magically appear, but they emerge from a gradual transformative process, and they can be helped along in this transformation. Going beyond the previously noted politically constrained U.S. federal Healthy Marriage and Responsible Fatherhood Initiative (ACF 2019), non-governmental community-based, parenting, social service, advocacy, and religious organizations, especially in the Black community, have taken the initiative to develop local fatherhood programs (e.g., Concerned Black Men of America, Omega Psi Phi Fraternity, etc.). These programs generally emphasize men's own social and psychological transformation and healing; paternal responsibility and generativity; and moral, spiritual, and psychological engagement with their children; as well as financial and social support of their families. They are backed up by national fatherhood resource and training organizations (e.g., The MGH Fatherhood Project, the National Fatherhood Initiative, Mr. Dad, etc.). These organizations explicitly counter the debilitating myths of Black men's non-involvement with their children.

The Healthy Start Initiative was the first and is currently the principal U.S. national $\mathrm{MCH}$ perinatal program to actively incorporate a positive mandate to address Fatherhood and Male Engagement (Healthy Start 2019). Its "Dads Matter Initiative," with its "Dads and Diamonds are Forever" curriculum, and an annual fatherhood conference, emphasizes father's "inclusion, involvement, investment and integration" across the life course, enhancing men's sense of value to himself, his children, the mothers of his children, and his community (i.e., generative fathering) (Harris and Brott 2018). Several other MCH programs, serving low-income communities in the U.S., such as home visiting, Head Start academic enrichment, and the WIC nutrition supplementation programs, also have begun to target and address father's needs, though not yet as systematically as Healthy Start (Davison et al. 2019).

The perinatal period for many men, as for women, is also a period of marked openness for behavioral, socio-emotional, and health changes (Addis and Mahalik 2003), wherein fatherhood imperatives can trump masculine stereotypes. Mental health, relational, and fathering skills can be taught (Knox et al. 2011; Levy et al. 2012; Tollestrup 2018). The transition from a more traditional distant fatherhood role to a more equitable child caretaking partnership may also free up men from other gendered sex role stereotypes that diminish their psychological capacities to experience and express emotions, acknowledge health needs, or treat their partners more respectfully. Father's psychological developmental transitions during the perinatal period however are not generally recognized or appreciated by most reproductive and primary health care professionals, nor are there programmatic services or support for men's growth as generative fathers (Pol et al. 2014; Johansson et al. 
2015). Much more research is needed to understand what facilitates the growth of men's paternal generativity, or even how best to measure it.

Similar to women, men's adult psychological developmental as a more generative parent is one of most important positive mental health impacts of pregnancy and early fatherhood, especially for the first time fathers. Paternal generativity doesn't just happen. While the momentum for paternal generativity must ultimately come from, and be empowered by, each man himself, all MCH and father-involving programs should consciously engage with and support his developmental maturation. We must go beyond the limited federal emphasis in the U.S. on men's financial and marital responsibilities only; and we must create, culturally and professionally, the paternal expectations and opportunities for men to celebrate the joys and deep satisfactions of fatherhood. Most fathers make the successful adult psychological transition to being a more generative parent and are happy to have done so.

\subsection{Men's Life Course Development as Fathers}

The development of generative responsible fathers reflects a gradual longitudinal process that has its roots long prior to the pregnancy conception and continues long after the delivery; and it can be helped and hindered all along the way. Paternal generativity is both personal and intergenerational. The perinatal period, the focus of this essay, is one of its principle sensitive periods of accelerated growth.

Kotelchuck and Lu (2017) in their publication on men and preconception health graphically highlight several key conceptual features about the growth of men's paternal generativity over the life course. To quote from that article:

"First, as with women's reproductive life course (Lu and Halfon 2003), it [Fig. 1, as reproduced here] encourages us to view men's health and development longitudinally, recognizing that the impact of his health and generativity transcends the moment of pregnancy conception, and appreciate the intergenerational continuity and the bi-directionality of men's health. Father's reproductive health and generativity is not fixed; each stage of life and health builds on both prior and current life and health experiences and evolves over the life course (Fine and Kotelchuck 2010). This new MCH fatherhood life course graphic acknowledges that some men have more negative or positive life experiences; that the root causes of men's reproductive health and paternal generativity reflects both the negative and positive social determinants influencing his past and current health - including his adverse childhood and adolescent experiences, sexual health education and socialization, current and past poverty, employment, and environmental and occupational exposures, etc. The paternal $\mathrm{MCH}$ life course model thus reflects both a resiliency and a deficit perspective. One's reproductive potential is not immutable. We can and must help build boys' and men's resiliency to achieve both the biology and paternal generativity of fatherhood, and thereby optimize both their own and their children's health and development. The men's reproductive health life course graphic also reminds us that there are multiple times and places to intervene to enhance (or diminish) men's health and paternal generativity." 


\section{Paternal Generativity Over the Life Course}

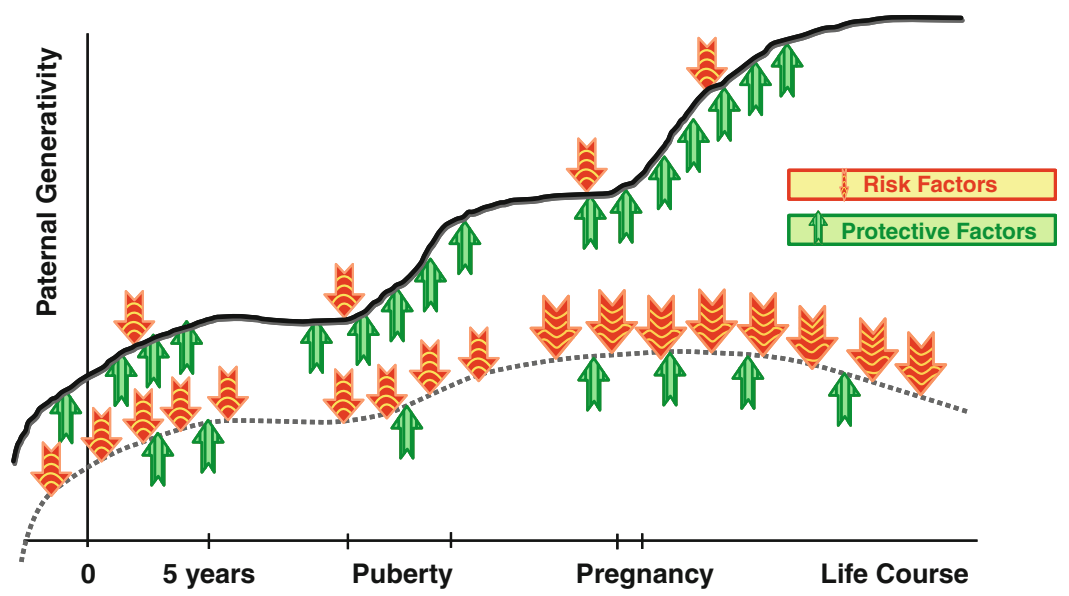

Fig. 1 How differential exposure to risk factors (downward arrows) and protective factors (upward arrows) over the life course affect developmental trajectories in father involvement/generativity. Lower involvement (dashed curve) results from cumulative exposure to more risk factors and less protective factors across the life span, particularly at sensitive periods of development. (Source: Kotelchuck and Lu 2017)

And although this graph focuses on men's individual generativity, efforts to encourage his shared responsibility for healthy parenthood and for equitable parental childcare and involvement must start earlier than conception with his shared responsibility for sexuality and family planning. Further, men's development as generative fathers must also necessarily address his pre-fatherhood adolescent social and gender norms, perhaps beginning in schools with their parenting, sexuality, and genderbased education programs. The preconception time period for paternal generativity must be pushed backwards in developmental ontological time.

Additionally, men's paternal generativity is not a simple linear age trend but is embedded within our larger human biologic development. The roots of men's intergenerational and epigenetic generativity starts before birth, and has at least two special sensitive periods of growth: puberty and the initial antenatal and early postnatal transition to fatherhood. The latter is perhaps the most sensitive transformational life course period for men's psychosocial development and maturation as a father (Genesoni and Tallandini 2009); it may perhaps also reflect a new paternal biological sensitive period due to his changing perinatal hormones and brain structure. The experiences and health consequences of fatherhood are further filtered through and modified by the men's pre-existing life course health and well-being that he brings into the perinatal period, similar to that of pregnant women.

Indeed, the differential risk and protective factors (the conceptual arrows in Fig. 1) influencing the growth of men's generativity over the life course can be 
viewed as reflecting the many contributors to the fatherhood health pathways already discussed throughout this chapter-including, for example, family income, workfamily stress, substance use, social connectedness, etc. These factors, in turn, are strongly modulated (positively or negatively) by national and state health, economic, and social welfare policies and programs-including both those operating in the immediate perinatal period (e.g., paid leave, living wages, health insurance access), as well as those operating long before (e.g., childhood health and education, masculinity gender role socialization and childhood SDOH).

Moreover, fathers are not homogeneous; different subgroups of fathers are likely to experience the life-course health and developmental challenges of fatherhood and fatherhood generativity differently, based on both their personal and socio-historical life course experiences. Potentially important fatherhood subgroups to consider might be based on socio-economic status, race/ethnicity, first-time or experienced fatherhood, teen or older paternal age, planned or unplanned pregnancy, residential status, disability status, incarceration, or military service. In the U.S., the experiences of poor fathers, especially those of color, are particularly challenging given historical structural racism and its ongoing negative health, social welfare, and employment biases. Too little is known about the life course sources of more positive father generativity.

The developmental roots of paternal generativity are not restricted only to the critical and sensitive perinatal period, but build off of men's prior life course health and developmental experiences. Paternal generativity should be viewed as an intergenerational and epigenetic phenomenon, building off of prior generations and towards future generations. Paternal generativity is not fixed but malleable. The momentum for paternal generativity, for fatherhood, with all its satisfactions and stresses, must be empowered by each man himself; but it is embedded in the larger developmental world in which his full reproductive potential is either encouraged and grows or is stunted and underachieved. The fatherhood life course perspective suggests that there are multiple places and times in which both positive and negative program and policy interventions and life experiences can influence men's paternal generativity. Paternal generativity, the essence of fatherhood, is shaped over his life course.

\section{Enhancing Fatherhood to Foster Men's Health and Development During the Perinatal Period: Implications for Research, Practice, and Policy}

Fatherhood profoundly impacts men's health and development. It impacts his physical, mental, and social health, and his sense of paternal generativity, both immediately and over his life course. These, in turn, impact his infant's, partner's, and family's health. Indeed, fatherhood can be viewed as a risk or resiliency factor 
for men's subsequent health across his life course. The focus on men's changing health as a consequence of fatherhood is an important new perspective for the $\mathrm{MCH}$ reproductive health field, which has historically focused on the mother and her health.

This chapter is one of a pair of inter-related chapters on father's health in the perinatal period that parallels the dual approach of the current women's preconception health movement, which simultaneously addresses the impact of the mother's perinatal health both on the infant's health outcomes and on the mother's own subsequent lifetime health. Both topics for men also are critical and intractably bound. Father's health, like mother's health, is thus similarly a bi-directional and inter-generational topic.

This chapter pulls together and articulates six broad pathways through which fatherhood could potentially positively or negatively impact men's health and development-men's pre-existing health, his perinatal changed physical, mental, and social health, his generativity, and his life-course experiences. This emerging conceptual framework encompasses the father's entire life course, but focuses here on the perinatal time period, a time frame not usually thought of as impacting on men's health. These six specific pathways are written to try to isolate and better articulate them, though many of them likely overlap and are synergistic. Several emerging themes merit further discussion.

First, going beyond the impact of fatherhood on men's physical and mental health, this chapter, in particular, emphasized and explored two new health topics: men's psychological maturation of paternal generativity, and men's social health and well-being. The first topic, men's psychological maturation into more generative fathers, is not a well articulated fatherhood topic, especially antenatally. It has not been the focus of virtually any formal $\mathrm{MCH}$ or prenatal health services to date, although a large popular "Advice for New Dads" social media literature exists, which may at times touch on this theme. The psychological empowerment of fathers requires, in part, that our current health service systems (and men themselves) overcome their traditional sexist assumptions about men's supposedly limited roles and needs, his marginality, during the pregnancy and early childhood period.

Second, men's social health and well-being may be a difficult pathway for the $\mathrm{MCH}$ reproductive health community to appreciate, as this topic links more broadly to men's larger social roles within the family home and employment. The transformative impact of fatherhood on men's social health, and therefore ultimately on reproductive health, is heavily influenced by social welfare and employment programs and policies, many of which are also closely linked to women's gender equity issues. This emerging pathway has the potential to bring the $\mathrm{MCH}$ community productively together with other business and human service professions that are grappling with similar paternal (and maternal) social health and well-being issues to create multi-sector transformative change (Bowles et al. 2021).

Third, this chapter further builds upon the growing recognition that fathers are a key vector for the SDOH and well-being of their families (Kotelchuck 2018, 2021), and begins to add a more nuanced understanding of this theme. As noted previously, this chapter emphasizes that men's own social well-being, his SDOH characteristics, 
are not fixed, but can change due to his experiences of fatherhood. Moreover, the father's historical and current compromised SDOH can diminish his positive health responses to fatherhood and limit his fullest and healthiest participation in the perinatal period and beyond. And, while paternal generativity is not principally determined by social class, poverty does make it harder for some men.

Fourth, the positive or negative impact of fatherhood on men's physical, mental, social, or generative health and development is not pre-ordained. This chapter, reflecting the limited existing literature, predominantly notes the negative paternal physical and especially mental health impacts of fatherhood. There is much less balanced research on the more positive health experiences of fatherhood, and how to foster them.

Fifth, this chapter documents that the impact of fatherhood on men's health begins before delivery (i.e., the perinatal roots of father's own health). It strongly reinforces the initial chapter's parallel efforts to expand the time frame for the impact of men's health on reproductive and infant health into the antenatal period. This essay however emphasizes not merely the perinatal impact of fatherhood on men's health, but an even longer ontological life course perspective on father's health. The health of men and their paternal generative characteristics start early, epigenetically, long before conception; although like for women, the experiences during the perinatal and early parenthood period seem to be an especially biologically sensitive period of impact. Fatherhood is not simply a sperm and post-partum parenting; paternal generativity must be conceptualized across the life course.

Sixth, this chapter and the prior one dispute the prevailing view that mothers and their health and well-being alone are solely responsible for positive reproductive and infant outcomes and that women are the only or primary gender affected by parenthood. If men actively assume or are encouraged to participate in the joys and responsibilities of reproductive and infant care, they will likely become more generative fathers, and in turn that could help free up women and men from overly prescribed gendered parental behavioral and economic roles. This chapter, while a self-contained $\mathrm{MCH}$ theme, has been inspired by, and hopefully contributes to, the larger social gender equity movement, as well as the growing parenting health and men's health movements.

Seventh, hopefully, this chapter and the prior one have demonstrated that a focus on father's health and well-being should be a more formal and important MCH perinatal health research, practice, and policy topic. These chapters provide an everstronger, positive, empirical and theoretical developmental science rationale to support more extensive, earlier, and healthier paternal perinatal involvement. The six pathways noted in this chapter summarize our current scientific knowledge base to date (Knowledge Base), which can now provide the basis to develop more effective targeted fatherhood programmatic and policy interventions (Social Strategies) and to support more effective and scientifically justified fatherhood advocacy efforts (Political Will) for their implementations (Richmond and Kotelchuck 1983).

Clearly the core public health action message of this chapter (and the prior one) is that there should be more active, earlier, and healthier paternal involvement in the perinatal period. Many of this chapter's six pathways call out for readily 
implementable ameliorative actions and interventions to address the added challenges of fatherhood on men's health. The fatherhood life course perspective further suggests that there are multiple places and times for potential synergetic interventions to enhance men's and father's health throughout his life course. Hopefully, this essay will add to the momentum for more targeted and effective father-oriented perinatal health interventions and policies-in order to ensure both more optimal reproductive and infant health and development and more optimal men's health, development, and paternal generativity.

This book highlights three key sectors for paternal program and policy interventions-social policy, work/organizational practices, and health care. No single sector alone can solely enhance the impact of fatherhood on men's health and development or assure greater parental gender equity for men and women; all sectors are needed and must be synergetically involved. Sadly, however, there is relatively little professional recognition of father's own unique perinatal health needs - and even less formal services directed towards him. This Conference and edited book reflect an effort to enhance fatherhood activities within each of three sectors and importantly across sectors (Bowles et al. 2021).

Fatherhood is a life course developmental achievement. Fatherhood is not a singular point in the life course, but a profoundly human experience that occurs over time and across generations. The developmental trajectory of fatherhood starts long before conception and impacts fathers and their children and family throughout their lives, long after conception and inter-generationally. Healthy and engaged fathers help insure healthy children, healthy families, healthy workforces, and healthy communities.

\section{References}

Abraham E, Hendler T, Shapira-Lichter I, Kanat-Maymon Y, Zagoory-Sharon O, Feldman R (2014) Father's brain is sensitive to childcare experiences. Proc Natl Acad Sci U S A 111 (27):9792-9797

Addis ME, Mahalik JR (2003) Men, masculinity and the contexts of help seeking. Am Psychol 58 (1):5-14

Administration for Children and Family (2019) Healthy marriage and responsible fatherhood. Office of Family Assistance. U.S. Department of Health and Human Services. www.acf.hhs. gov/ofa/programs/healthy-marriage

Almond D, Rossin-Slater M (2013) Paternity acknowledgement in two million birth records in Michigan. PLoS One 8(7):e70042. https://doi.org/10.1371/journal.pone.0070042

Baldwin S, Bick D (2018) Mental health of first time fathers-it's time to put evidence into practice. JBI Database Syst Rev Implement Rep 16(11):2064-2065

Baldwin S, Malone M, Sandall J, Bick D (2018) Mental health and well-being during the transition to fatherhood: a systematic review of first time fathers' experiences. JBI Database Syst Rev Implement Rep 16(11):2118-2219

Bertakis KD, Rahman A, Jay Helms L, Callahan EJ, Robbins JA (2000) Gender differences in the utilization of health care services. J Fam Pract 49(2):147-152

Boggess J, Price A, Rodriguez N (2014) What we want to give our children: how child support debt can diminish wealth-building opportunities for struggling black fathers and their family. Center 
for Family Policy and Practice, Madison. https://cffpp.org/wp-content/uploads/ whatwewanttogiveourkids.pdf

Bowles HR, Kotelchuck M, Grau-Grau M (2021) Reducing barriers to engaged fatherhood: three principles for promoting gender equity in parenting. In: Grau-Grau M, las Heras M, Bowles HR (eds) Engaged fatherhood for men, families and gender equality. Springer, Cham, pp 299-325

Brennan A, Ayers S, Ahmed H, Marshall-Lucette S (2007) A critical review of the couvade syndrome: the pregnant male. J Reprod Infant Psychol 25(3):173-189

British Broadcasting Corporation News (2009) Fathers-to-be 'gain extra weight'. https://news.bbc. co.uk/2/hi/health/8063004.stm

Budig M, Hodges MJ (2014) Statistical models and empirical evidence for differences in the motherhood wage penalty across the earnings distribution: a reply to Killewald and Bearek. Am Sociol Rev 79(20):358-364

Burgard SA, Ailshire JA (2013) Gender and time for sleep among US adults. Am Sociol Rev 78 (1):51-69

Canadian Tobacco Use Monitoring Survey (2006) Via Health Canada Website. https://www.Hc-Sc. Gc.Ca

Carlson MJ, Mclanahan SS, Brooks-Gunn J (2008) Coparenting and non-residential involvement with young children after non-marital birth. Demography 45(2):461-488

Centers for Disease Control and Prevention (CDC) (2019) Preconception health and health care. https://www.cdc.gov/preconception/index. Accessed 15 Jan 2019

Cheng ER, Kotelchuck M, Gerstein ED, Taveras EM, Poehlmann-Tynan J (2016) Postnatal depressive symptoms among mothers and fathers of infants born preterm: prevalence and impacts on children's early cognitive function. J Dev Behav Pediatr 37(1):33-42

Choiriyyah I, Sonenstein FL, Astone NM, Pleck JH, Dariotis JK, Marcell AV (2015) Men aged 15-44 in need of preconception care. Matern Child Health J 19(11):2358-2365

Coleman PK, Karraker KH (1998) Self-efficacy and parenting quality: findings and future applications. Dev Rev 18(1):47-85

Correl SJ, Benard S, Paik I (2007) Getting a job: is there a motherhood penalty? Am J Sociol 112 (5):1297-1339

Darwin Z, Galdas P, Hinchliff S, Littlewood E, McMillan D, McGowan L, Gilbody S, on behalf of the Born and Bred in Yorkshire (BaBY) Team (2017) Fathers' views and experiences of their own mental health during pregnancy and the first postnatal year: a qualitative interview study of men participating in the UK Born and Bred in Yorkshire (BaBY) cohort. BMC Pregnancy Childbirth 17(1):45. https://doi.org/10.1186/s12884-017-1229-4

Davison KK, Gavarkovs A, McBride B, Kotelchuck M, Levy R, Taveras EM (2019) Engaging fathers in early obesity prevention during the first thousand days: policy, systems and environmental change strategies. Obesity 27(4):523-533

Dollahite DC, Hawkins AJ, Brotherson SE (1997) Fatherwork: a conceptual ethic of fathering as generative work. In: Hawkins AJ, Dollahite DC (eds) Generative fathering: beyond deficit perspectives. Sage, Thousand Oaks, pp 17-35

Due C, Chiarolli S, Riggs DW (2017) The impact of pregnancy loss on men's health and wellbeing: a systemic review. BMC Pregnancy Childbirth 17:380. https://doi.org/10.1186/s12884-017$1560-9$

Edelstein RS, Wardecker BM, Chopik WJ, Moors AC, Shipman EL, Lin NJ (2015) Prenatal hormones in first-time expectant parents: longitudinal changes and within couple correlations. Am J Hum Biol 27(3):317-325

Edin K, Nelson TJ (2013) Doing the best I can: fatherhood in the Inner City. University Of California Press, Berkeley

Edvardsson K, Lindkvist M, Eurenius E, Mogren I, Small R, Ivarsson A (2013) A population-based study of overweight and obesity in expectant parents: socio-demographic patterns and withincouple associations. BMC Public Health 13(1):923. https://doi.org/10.1186/1471-2458-13-923

Edwards BN, McLemore MR, Baltzell K, Hodgkin A, Nunez O, Franck LS (2020) What about the men? Perinatal experiences of men of color whose partners were at risk for preterm birth, a 
qualitative study. BMC Pregnancy Childbirth 20:91. https://doi.org/10.1186/s12884-0202785-6

Eggebeen DJ, Knoester C (2001) Does fatherhood matter for men? J Marriage Fam 63(2):381-393 Erikson EH (1950) Childhood and society. Norton, New York

Fine A, Kotelchuck M (2010) Rethinking MCH: the life course model as an organizing framework: concept paper. U.S. Department of Health and Human Services, Health Resources and Services Administration, Maternal and Child Health Bureau, Rockville

Fleming AS, Ruble D, Howard K, Wong PY (1997) Hormonal and experiential correlates of maternal responsiveness during pregnancy and the puerperium in human mothers. Horm Behav 31:145-158

Freeman E, Fletcher R, Collins CE, Morgan PJ, Burrows T, Callister R (2012) Preventing and treating childhood obesity: time to include the father. Int J Obes 36(1):12-15

Frey KA, Navarro SM, Kotelchuck M, Michael CL (2008) The clinical content of preconception care: preconception care for men. Am J Obstet Gynecol 199(6 Suppl B):S389-S395

Garfield CF, Isacco A, Bartlo WD (2010) Men's health and fatherhood in urban Midwestern United States. Int J Mens Health 9(3):161-174

Garfield CF, Duncan G, Rutsohn J, McDade TW, Adam EK, Coley RL, Lindsay Chase-Lansdale P (2014) A longitudinal study of paternal mental health during transition to fatherhood as young adults. Pediatrics 133(5):836-843

Garfield CF, Duncan G, Gutina A, Rutsohn J, McDade TW, Adam EK, Coley RL, Lindsay ChaseLansdale P (2016) Longitudinal study of body mass index in young males and the transition to fatherhood. Am J Mens Health 10(6):NP158-NP167

Gemayel DJ, Wiener KKK, Saliba AJ (2018) Development of a conception framework that identifies factors and challenges impacting perinatal fathers. Heliyon 4(7):e00694

Genesoni L, Tallandini MA (2009) Men's psychological transition to fatherhood: an analysis of the literature, 1989-2008. Birth 36(4):305-318

Gettler LT, McDade TW, Feranil AB, Kuzawa CW (2011) Longitudinal evidence that fatherhood decreases testosterone in human males. Proc Natl Acad Sci U S A 108(39):16194-16199

Glass JL, Simon RW, Andersson MA (2016) Parenthood and happiness: effects of work-family reconciliation policies in 22 OECD countries. Am J Sociol 122(3):886-929

Gordon I, Zagoory-Sharon O, Leckman JF, Feldman R (2010) Prolactin, oxytocin and the development of paternal behavior across the first six months of fatherhood. Horm Behav 58 (3):513-518

Grebe NM, Sarafin RE, Strenth CR, Zilioli S (2019) Pair-bonding, fatherhood, and the role of testosterone: a meta-analytic review. Neurosci Biobehav Rev 98:221-233

Grundy E, Kravdal $\varnothing$ (2008) Reproductive history and mortality in late middle age among Norwegian men and women. Am J Epidemiol 167(3):271-279

Gustafsson E, Levréro F, Reby D, Mathevon N (2013) Fathers are just as good as mothers at recognizing the cries of their baby. Nat Commun 4:1698

Harrington B (2021) The new dad: the career-caregiving conundrum. In: Grau-Grau M, las Heras M, Bowles HR (eds) Engaged fatherhood for men, families and gender equality. Springer, Cham, pp 197-212

Harrington B, Van Deusen F, Fraone J (2014) The new dad: take your leave. Boston College Center for Work \& Family, Chestnut Hill

Harris K, Brott A (2018) NHSA healthy start fathers-real life, real dads. National Healthy Start Association, Washington, DC. https://www.nationalhealthystart.org/what_we_do/male_ involvement/nhsa_healthy_start_fathers_real_life_real_dads

Hashemian F, Shafigh F, Roohi E (2016) Regulatory role of prolactin in paternal behavior in male parents: a narrative review. J Postgrad Med 62(3):182-187

Hawkins AJ, David C (1997) Beyond the role-inadequacy perspective. In: Hawkins AJ, Dollahite DC (eds) Generative fathering: beyond deficit perspectives. Sage, Thousand Oaks, pp 3-16

Hawkins AJ, Dollahite DC (eds) (1997) Generative fathering: beyond deficit perspectives. Sage, Thousand Oaks 
Healthy Start (2019) Health resources and service administration-maternal and child health. https://mchb.hrsa.gov/maternal-child-health-initiatives/healthy-start

Hobson B, Fahlen S (2009) Competing scenarios for European fathers: applying Sen's capabilities and agency framework to work-family balance. Ann Am Acad Pol Soc Sci 624(1):214-233

Hodges MJ, Budig MJ (2010) Who gets the daddy Bonus? Markers of hegemonic masculinity and impact of first-time fatherhood on men's earnings. Gend Soc 24(6):715-745

Hull EE, Rofey DL, Robertson RJ, Nagle EF, Otto AD, Aaron DJ (2010) Influence of marriage and parenthood on physical activity: a 2-year prospective analysis. J Phys Act Health 7(5):577-583

Humberd B, Ladge J, Harrington B (2015) The 'new' dad: navigating father identity within organizational contexts. J Bus Psychol 30(2):249-266

Johansson M, Fenwick J, Premberg A (2015) A meta-synthesis of the father's experiences of their partner's labour and birth. Midwifery 31(1):9-18

Jomeen J (2017) Fathers in the birth room: choice or coercion? Help or hinderance? J Reproduct Infant Psychol 35(4):321-323

Kazmierczak M, Kielbratowska B, Pastwa-Wojciechowska B (2013) Couvade syndrome among polish expectant fathers. Med Sci Monit 21(19):132-138

Keizer R, Dykstra PA, van Lenthe FJ (2011) Parity and men's mortality risks. Eur J Pub Health 22 (3):343-347

Kessler RC, Berglund P, Demler O, Jin R, Koretz D, Merikangas KR, John Rush A, Walters EE, Wang PS (2003) The epidemiology of major depressive disorder: results from the National Comorbidity Survey Replication (NCS-R). JAMA 289(35):3095-3105

Kim P, Swain JE (2007) Sad dads: paternal post-partum depression. Psychiatry (Edgmont) 4 (2):35-47

Kim P, Rigo P, Mayes LC, Feldman R, Leckman JF, Swain JE (2014) Neural plasticity in fathers of human infants. Soc Neurosci 9(5):522-535

Knox V, Cowan PA, Cowan CP, Bildne E (2011) Policies that strengthen fatherhood and family relationships: what do we know and what do we need to know? Ann Am Acad Pol Soc Sci 635 (1):216-239

Kotelchuck M (2018) Looking back to move forward: a return to our roots, addressing social determinants across MCH history. In: Verbiest S (ed) Moving life course theory into practice: making change happen. APHA Press, Washington, DC, pp 57-78. https://ajph. aphapublications.org/doi/10.2105/9780875532967ch03

Kotelchuck M (2021) The impact of father's health on reproductive and infant health and development. In: Grau-Grau M, las Heras M, Bowles HR (eds) Engaged fatherhood for men, families and gender equality. Springer, Cham, pp 31-61

Kotelchuck M, Lu M (2017) Father's role in preconception health. Matern Child Health J 21 (11):2025-2039

Kvande E (2021) Individual parental leave for fathers-promoting gender equality in Norway. In: Grau-Grau M, las Heras M, Bowles HR (eds) Engaged fatherhood for men, families and gender equality. Springer, Cham, pp 153-162

Ladge JJ, Humberd BK (2021) Impossible standards and unlikely trade-offs: can fathers be competent parents and professionals? In: Grau-Grau M, las Heras M, Bowles HR (eds) Engaged fatherhood for men, families and gender equality. Springer, Cham, pp 183-196

Ladge JJ, Humberd BK, Baskerville M, Harrington B (2015) Updating the organizational man: fathers in the workplace. Acad Manag Perspect 29(1):152-171

Lamb ME (1975) Fathers: forgotten contributors to child development. Hum Dev 18(4):245-266

Lamb ME (ed) (2010) The role of the father in child development, 5th edn. Wiley, New York

Leach LS, Poyser C, Cooklin AR, Giallo R (2016) Prevalence and course of anxiety disorders (and symptom levels) in men across the perinatal period: a systematic review. J Affect Disord 190 (15):675-686

Levy RA, Kotelchuck M (2021) Fatherhood and reproductive health in the antenatal period: from men's voices to clinical practice. In: Grau-Grau M, las Heras M, Bowles HR (eds) Engaged fatherhood for men, families and gender equality. Springer, Cham, pp 111-137 
Levy RA, Badalament J, Kotelchuck M (2012) The Fatherhood Project. Massachusetts General Hospital, Boston. www.thefatherhoodproject.org

Lipkin M, Lamb GS (1982) The couvade syndrome: an epidemiological study. Ann Intern Med 96 (4):509-511

Lu MC, Halfon N (2003) Racial and ethnic disparities in birth outcomes: a life-course perspective. Matern Child Health J 7(1):13-30

Martin JA, Hamilton BE, Osterman MJK, Driscoll AK (2019) Births: final data for 2018. Natl Vital Stat Rep 68(13):1-47

Masoni S, Maio A, Trimarchi G, de Punzio C, Fioretti P (1994) The couvade syndrome. J Psychosom Obstet Gynecol 15(3):125-131

May C, Fletcher R (2013) Preparing fathers for the transition to parenthood: recommendations for the content of antenatal education. Midwifery 29(5):474-478

McLanahan S, Tach L, Schneider D (2013) The causal effects of father absence. Annu Rev Sociol 399(1):399-427

McLean CP, Asnaani A, Litz BT, Hofmann SG (2011) Gender differences in anxiety disorders. J Psychiatr Res 45(8):1027-1035

Modig K, Talbäck M, Torssander J, Ahlbom A (2017) Payback time? Influence of having children on mortality in old age. J Epidemiol Community Health 71(5):424-430

Nannini A, Lazar J, Berg C, Tomashek K, Cabral H, Barger M, Barfield W, Kotelchuck M (2008) Injury: a major cause of pregnancy-associated morbidity in Massachusetts. J Midwifery Womens Health 53(1):3-10

National Academies of Sciences, Engineering, and Medicine (NASEM) (2016) Parenting matters: supporting parents of children ages 0-8. The National Academies Press, Washington, DC

National Academies of Sciences, Engineering, and Medicine (NASEM) (2019) Vibrant and healthy kids: aligning science, practice, and policy to advance health equity. The National Academies Press, Washington, DC

Nepomnyaschy L, Waldfogel J (2007) Paternity leave and fathers' involvement with their young children: evidence from the American ECLS-B. Community Work Fam 10(4):427-453

Paulson JF, Bazemore SD (2010) Prenatal and postpartum depression in fathers and its association with maternal depression: a meta-analysis. JAMA 303(19):1961-1969

Persson P, Ross-Slater M (2019) When dad can stay home: fathers' workplace flexibility and maternal health. IZA Institute of Labor economics discussion paper no. 12386

Petts RJ, Carlson DL, Chris KC (2019) If I[take] leave, will you stay? Paternity leave and relationship stability. J Soc Policy 49(4):829-849. https://doi.org/10.1017/ S0047279419000928

Philpott LF, Leahy-Warren P, FitzGerald S, Savage E (2017) Stress in fathers in the perinatal period: a systematic review. Midwifery 55:113-127

Philpott LF, Savage E, FitzGerald S, Leahy-Warren P (2019) Anxiety in fathers in the perinatal period: a systemic review. Midwifery 76:54-101

Pol HL, Koh SSL, He H (2014) An integrative review of fathers' experiences during pregnancy and childbirth. Int Nurs Rev 61(4):543-554

Ramchandani PG, Stein A, O’Connor TG, Heron J, Murray L, Evans J (2008) Depression in men in the postnatal period and later child psychopathology: a population cohort study. J Am Acad Child Adolesc Psychiatry 47(4):390-398

Richmond JB, Kotelchuck M (1983) Political influences: rethinking national health policy. In: McGuire CH, Foley RP, Gorr D, Richards RW (eds) Handbook of health professions education. Josey-Bass, San Francisco, pp 386-404

Rolling JK, Mascaro JS (2017) The neurobiology of fatherhood. Curr Opin Psychol 15:26-32

Roubinov DS, Luecken LJ, Gonzales NA, Crnic KA (2016) Father involvement in Mexico-origin families: preliminary development of a culturally informed measure. Cultur Divers Ethnic Minor Psychol 22(2):277-287

Saxbe DE, Edelstein RS, Lyden HM, Wardecker BM, Chopik WJ, Moors AC (2017) Fathers' decline in testosterone and synchrony with partner testosterone during pregnancy predicts greater post-partum relationship investment. Horm Behav 90:39-47 
Saxbe D, Corner G, Khaled M, Horton K, Wu B, Khoddam H (2018) The weight of fatherhood: identifying mechanisms to explain paternal perinatal weight gain. Health Psychol Rev 12 (3): $1-38$

Singley DB, Edwards LM (2015) Men's perinatal mental health in transition to fatherhood. Prof Psychol Res Pract 46(5):309-316

Smith JA, Braunack-Mayer A, Wittert G (2006) What do we know about men's help-seeking and health service use? Med J Aust 184(2):81-83

Steen M, Downe S, Bamford N, Edozien L (2012) Not-patient and not-visitor: a metasynthesis father's encounters with pregnancy, birth, and maternity care. Midwifery 28(4):362-371

Tollestrup J (2018) Fatherhood initiatives: connecting fathers to their children. Congressional Research Service. RL31025. www.crsreports.congress.gov.

Umberson D, Liu H, Mirowsky J, Reczek C (2011) Parenthood and trajectories of change in body weight over the life course. Soc Sci Med 73(9):1323-1331

United States Bureau of the Census (2018) Current population survey: annual social and economic supplement survey, United States, 2017 (ICPSR 37075). https://doi.org/10.3886/ ICPSR37075.v1

Wise PH (2008) Transforming preconceptional, prenatal, and interconceptional care into a comprehensive commitment to women's health. Womens Health Issues 18(6 Suppl):S13-S18

Yogman MW, Eppel AM (2021) The role fathers in child and family health. In: Grau-Grau M, las Heras M, Bowles HR (eds) Engaged fatherhood for men, families and gender equality. Springer, Cham, pp 15-30

Yogman MW, Garfield CF, the Committee on Psychosocial Aspects of Child and Family Health (2016) Fathers' roles in the care and development of their children: the role of pediatricians. Pediatrics 138(1):e20161128

Open Access This chapter is licensed under the terms of the Creative Commons Attribution 4.0 International License (http://creativecommons.org/licenses/by/4.0/), which permits use, sharing, adaptation, distribution and reproduction in any medium or format, as long as you give appropriate credit to the original author(s) and the source, provide a link to the Creative Commons license and indicate if changes were made.

The images or other third party material in this chapter are included in the chapter's Creative Commons license, unless indicated otherwise in a credit line to the material. If material is not included in the chapter's Creative Commons license and your intended use is not permitted by statutory regulation or exceeds the permitted use, you will need to obtain permission directly from the copyright holder.

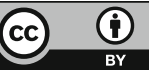

